\title{
Comparison of Carbon and Main Ion Radiation Profiles in Matched Helium and Deuterium Plasmas in JET
}

M.E. Fenstermacher, K.D. Lawson, G.D. Porter, S.K. Erents, C. Ingesson, G.F. Matthews, G.M. McCracken, $V$. Philipps, R.A. Pitts, M.F. Stamp

This article was submitted to

PSI-15 2002 Gifu $15^{\text {th }}$ International Conference on Plasma Surface Interactions (PSI) in Controlled Fusion Devices, Gifu, Japan, May 27-31, 2002

U.S. Department of Energy

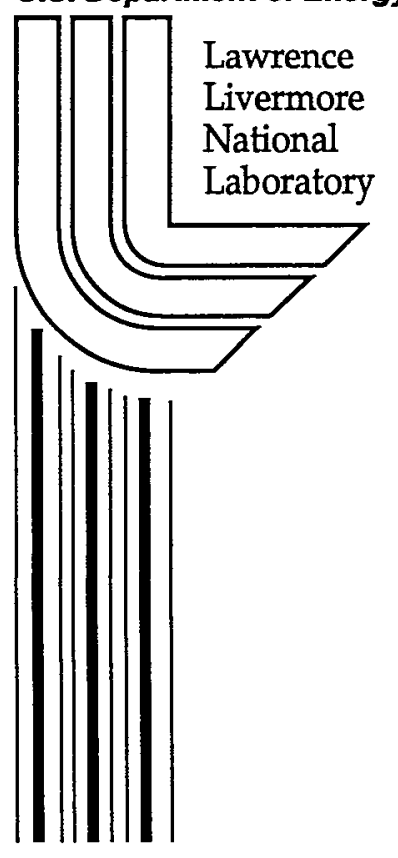




\section{DISCLAIMER}

This document was prepared as an account of work sponsored by an agency of the United States Government. Neither the United States Government nor the University of California nor any of their employees, makes any warranty, express or implied, or assumes any legal liability or responsibility for the accuracy, completeness, or usefulness of any information, apparatus, product, or process disclosed, or represents that its use would not infringe privately owned rights. Reference herein to any specific commercial product, process, or service by trade name, trademark, manufacturer, or otherwise, does not necessarily constitute or imply its endorsement, recommendation, or favoring by the United States Government or the University of California. The views and opinions of authors expressed herein do not necessarily state or reflect those of the United States Government or the University of California, and shall not be used for advertising or product endorsement purposes.

This is a preprint of a paper intended for publication in a journal or proceedings. Since changes may be made before publication, this preprint is made available with the understanding that it will not be cited or reproduced without the permission of the author.

This report has been reproduced directly from the best available copy.

Available electronically at http://www.doe.gov/bridge

Available for a processing fee to U.S. Department of Energy and its contractors in paper from

U.S. Department of Energy

Office of Scientific and Technical Information P.O. Box 62

Oak Ridge, TN 37831-0062

Telephone: (865) 576-8401

Facsimile: (865) 576-5728

E-mail: reports@adonis.osti.gov

Available for the sale to the public from

U.S. Department of Commerce

National Technical Information Service

5285 Port Royal Road

Springfield, VA 22161

Telephone: (800) 553-6847

Facsimile: (703) 605-6900

E-mail: orders@ntis.fedworld.gov

Online ordering: http://www.ntis.gov/ordering.htm

\section{OR}

Lawrence Livermore National Laboratory

Technical Information Department's Digital Library

http://www.llnl.gov/tid/Library.html 


\title{
Comparison of Carbon and Main Ion Radiation Profiles in Matched Helium and Deuterium Plasmas in JET
}

\author{
M.E. Fenstermacher, ${ }^{a}$ K. D. Lawson, ${ }^{b}$ G.D. Porter, ${ }^{a}$ S.K. Erents, ${ }^{b}$ C. Ingesson, ${ }^{c}$ \\ G. F. Matthews, ${ }^{b}$ G. M. McCracken, ${ }^{b}$ V. Philipps, ${ }^{\text {d }}$ R. A. Pitts, ${ }^{\mathrm{e}}$ M. F. Stamp, ${ }^{\mathrm{b}}$ \\ and Contributors to the EFDA-JET Workprogramme
a Lawrence Livermore National Laboratory, Livermore, California, USA at the DIII-D National Fusion Facility,
*Corresponding author Tel:+1-858-455-4159, e-mail: max.fenstermacher@gat.com General Atomics, P.O. Box, 85608, San Diego, California, 92186 USA

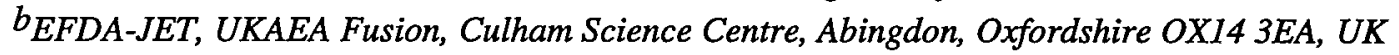
$c_{F O M}$ Instituut voor Plasmafysica Rijnhuizen, EURATOM Assoc., Postbus 1207, NL-3430 BE Nieuwegein, Netherlands

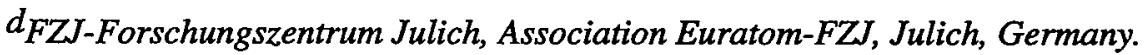
${ }^{e}$ CRPP -Ecole Polytechnique Federale de Lausanne, Association Euratom-Confederation Suisse, Lausanne, Switzerland

\begin{abstract}
This paper examines the radiation profiles and corresponding ionization source profiles of various carbon and main plasma ions in matched helium and deuterium L-mode plasmas in JET. Operation in helium should reduce chemical sputtering of carbon substantially compared with deuterium. The radiation intensities from $\mathrm{C}^{1+}, \mathrm{C}^{2+}$ and $\mathrm{C}^{3+}$ in the helium plasmas showed reduction by factors of 8,10 and 25 respectively along the inner SOL and divertor leg compared with the deuterium cases. However, the emission in the outer divertor leg was less than a factor of 2 lower in helium. Using photon efficiencies calculated by the UEDGE code for the spectrometer lines of sight, the calculated source rates of $\mathrm{C}^{1+}$ and $\mathrm{C}^{3+}$ along the inner SOL and inner divertor were reduced by a factors of 4 and 20 respectively in the helium plasmas. In the outer divertor leg the source rate of $\mathrm{C}^{3+}$ was reduced by a factor of 10 but the $\mathrm{C}^{1+}$ source rate did not change in helium. These measurements are consistent with a model that chemical sputtering of carbon dominates the source from the inner wall and inner divertor in deuterium L-mode plasmas while physical sputtering appears to dominate the source from the outer divertor.
\end{abstract}




\section{Introduction}

In tokamaks operated with graphite walls and deuterium plasmas, carbon impurities play a significant role in the radiation distribution and power balance for the Scrape-off-Layer (SOL) and divertor plasmas. One way to substantially change the carbon effects in the divertor, for comparison against predictive theories, is to change the working gas from deuterium (D) to helium (He). In helium plasmas the source of carbon due to chemical sputtering is expected to be small and the cross sections for charge exchange and ionization are different so the divertor conditions should change substantially, thereby testing the models.

Helium plasma discharges with helium neutral beam injection and operating conditions matched to previous deuterium discharges were obtained in a recent EFDA-JET campaign. Carbon, deuterium and helium visible emission data from fixed views of the divertor and VUV emission data from a poloidally scanning view of the inner and outer SOLs and the divertor show significant differences by region between helium and deuterium plasma operation. This paper focuses on a comparison of radiation profiles and implied carbon source rates in matched L-mode deuterium and helium plasmas in a JET high clearance equilibrium shape. The responses of the source rates in helium plasmas as functions of injected power and plasma density are also examined.

\section{Description of experiments}

The matched helium and deuterium plasmas for this study used a JET high clearance equilibrium shape, Fig. 1. Vertical sweeps of the divertor strikepoints were done to provide detailed profiles of plasma parameters in the divertor from target Langmuir probes, IRTV and bolometers. Basic operational parameters were: major radius, $R=2.9 \mathrm{~m}$, minor radius, $\mathrm{a}=0.9 \mathrm{~m}$, elongation, $\kappa=1.7$, plasma current, $\mathrm{I}_{\mathrm{p}}=2.4 \mathrm{MA}$, toroidal field, $\mathrm{B}_{\mathrm{T}}=2.4 \mathrm{~T}$, and safety factor, $q 95=2.7$. 
Time histories of injected neutral beam power, line averaged density, plasma effective charge and divertor strikepoint positions are shown in Fig. 2 for the four L-mode discharges used in this paper. In the helium and deuterium plasmas that nearly match, $\mathrm{P}_{\mathrm{nb}} \sim 2.4-3.2 \mathrm{MW}$ and $\mathrm{n}_{\mathrm{e}}=$ $3.6 \times 10^{20} \mathrm{~m}^{-3}$. One of the other helium discharges had higher power, $P_{n b}=5.4 \mathrm{MW}$ at comparable density and the final helium discharge had higher density, $\mathrm{n}_{\mathrm{e}}=7.0 \times 10^{20} \mathrm{~m}^{-3}$ at comparable power.

The primary diagnostics measurements used for the poloidal profile analysis are UV CIV and He II from a vertically viewing scanning VUV spectrometer (KT1) and visible CII from a vertically viewing camera $(\mathrm{KL} 2 \mathrm{C})$. Both of these diagnostics view the plasma from the top with wide views of the divertor and part of the SOL regions. For the helium discharges the two detectors of the KT1 instrument were set to the $31.2 \mathrm{~nm}$ CIV line and the $3 \mathrm{rd}$ order $(91.1 \mathrm{~nm})$ of the $30.3 \mathrm{~nm} \mathrm{He}$ II line. In the deuterium plasma KT1 also gives information on CIV. The KL2C camera measures intensity of the $658 \mathrm{~nm}$ visible CII line for all of the discharges considered here. Finally, calibrated measurements of $465 \mathrm{~nm}$ CIII emission from wide angle chords viewing horizontally at the midplane and vertically into the inner and outer divertor regions are available from the KS3 spectrometer for all of the discharges.

\section{Analysis}

Visible and UV emission profile data from the vertical views of the divertor and SOL showed significant reductions in carbon emission in the inner divertor and SOL helium compared with deuterium plasma operation but less change in the outer divertor. An example of the differences in CII visible emission is shown in Fig. 3. For the matched discharges at $57.5 \mathrm{~s}$ when the densities are comparable, the carbon emission in He plasma in the outer divertor leg is only about a factor of 2 lower than in the D plasma. However the emission is significantly lower in helium for the inner leg (factor of 10) and the midplane SOL (factor of 12) than in deuterium. At higher power in helium the $\mathrm{CII}$ emission in the outer leg increased to the level of the 
deuterium plasma but the emission in the inner leg and at the midplane was still much lower (factors of 3 and 5 respectively) than in deuterium. Finally at comparable power but higher density in helium the $\mathrm{CIII}$ decreased to low values in all views.

\subsection{UEDGE modeling}

To quantify the differences in carbon behavior between helium and deuterium plasmas in terms of sources the UEDGE fluid plasma code [1] was used to calculate an average photon efficiency, $\mathrm{S} / \mathrm{XB}$, for the measured wavelengths and lines of sight of several of the diagnostics. In each UEDGE simulation the plasma consisted of a combination of deuterium ions and neutrals, 2 charge states of helium ions plus neutrals, and 6 charges states of carbon ions plus neutrals. Consistent with measurements a $2 \%$ helium impurity was assumed for the deuterium simulation and a $2 \%$ deuterium impurity was used in the helium cases. A diffusive fluid model was used for the neutrals. For deuterium the full set of fluid equations was solved including ion continuity and parallel momentum equations with classical parallel and anomalous perpendicular viscosities. For the helium and carbon ions only a simplified equation balancing pressure gradient, friction, electrostatic and temperature gradient forces was solved

$$
F_{\text {total }}=-\frac{1}{n} \frac{d p}{d s}+m \frac{\left(v_{D}-v\right)}{\tau_{S}}+Z e E+\alpha \frac{d T_{e}}{d s}+\beta_{i} \frac{d T_{i}}{d s}=0 .
$$

Here $\mathrm{s}$ is the coordinate along the field line, $\mathrm{p}$ is the total pressure, $\mathrm{v}_{\mathrm{D}}$ is the deuterium ion velocity, $\tau_{\mathrm{S}}$ is the Spitzer collision time, $\mathrm{Z}$ is the impurity ion charge, $\mathrm{E}$ the parallel electric field and $\alpha_{e}$ and $\beta_{I}$ are constants of order $Z^{2}$. Deuterium charge exchange effects were included but no model of helium charge exchange was available. Models for both physical and chemical sputtering of carbon by deuterium and helium were used [2]. Uniform poloidal transport coefficients were $\mathrm{D}=0.35$ and $\mathrm{X}=0.70 \mathrm{~m}^{2} / \mathrm{s}$ for particles and energy respectively. Simulations with these coefficients produced good matches with measured upstream radial profiles of density and temperature (Fig. 4). Reasonably good matches between the target profiles of $J_{s a t}, n_{e}$ and $T_{e}$ measured by the probes and the simulation profiles were obtained by adjusting the local 
recycling coefficients for ions and neutrals independently at the inner and outer target plates (Fig. 5). For the purpose of calculating a credible $\mathrm{S} / \mathrm{XB}$ to use with the emission measurements this was the easiest way to get the simulation solutions to nearly match the in-out asymmetry of the downstream measurements. The largest difference between simulation and target measurements was in the helium cases where the simulation tended to overestimate the temperature near the inner target plate by up to a factor of 2 compared with the probe measurements. This will tend to overestimate the S/XB value in the inner divertor by comparable factors for the helium cases so that the source rates inferred from the emission measurements should be interpreted as upper limits in the inner divertor. Finally, since the plates should saturated a better model would use unity recycling on all targets. There are indications that combining this with the UEDGE model for poloidal particle drifts due to ion $\nabla \mathrm{B}$ and $\mathrm{E} \times \mathrm{B}$ effects [3] may help the simulations match the in-out asymmetry of the measurements; work on these simulations is in progress.

\subsection{Comparison of carbon source rates}

Comparison of poloidal profiles of CII visible and CIV UV emission show that helium operation has a significant effect on the source of low charge states of carbon in the inner divertor region and on the level of higher charge states of carbon throughout the divertor. CII $(658 \mathrm{~nm})$ profile data from the KL2C visible spectrometer and CIV (31.2 nm) profile data from the KT1 scanning UV spectrometer are shown in Fig. 6. The radiation profiles [Fig. 6(a,c)] show a factor of 8 reduction in the inner divertor region emission for CII. The reduction of CIV emission is by a factor of 25 in the inner divertor and a factor of 10 in the outer divertor in the helium plasmas. These reduction factors are very similar to those seen in helium plasmas in DII-D [4]. However the CII emission in the outer divertor region is comparable with that in deuterium plasmas. Converting to sources [Fig. 6(b,d)] using the S/XB values calculated by UEDGE, the data show the reduction in $\mathrm{C}^{1+}$ source in the inner divertor is a factor of 4 and the reduction in the source of $\mathrm{C}^{3+}$ is more than a factor of 12 throughout the divertor region. The 
$\mathrm{C}^{1+}$ source in the outer divertor region is comparable in helium and deuterium. These data indicate that the carbon sources from the inner divertor region, or perhaps the main chamber wall outside the spectrometer views, are more important for determining the source of the high charge states of carbon that get into the core plasma than the source in the outer divertor leg.

Comparisons of the emission profiles in helium plasmas as functions of injected power and density show that increasing the power increased the carbon and helium source rates in the divertor; in contrast, increasing the density decreased the carbon production in the divertor and increased the helium sources in the SOL outside the divertor. The $\mathrm{C}^{1+}$ and $\mathrm{C}^{3+}$ data are shown in Fig. 7 and the $\mathrm{He}^{1+}$ data are shown in Fig. 8. When the injected power was increased at constant density the emission of $\mathrm{CII}$ increased in both divertor legs and the inferred source rate of $\mathrm{C}^{1+}$ increased in the outer divertor [Fig. 7(a,b)]. The CIV radiation increased in both divertors and the $\mathrm{C}^{3+}$ source increased, primarily in the outer divertor [Fig. 7(c,d)]. The $\mathrm{He}^{1+}$ emission and source increased slightly in the divertors (Fig. 8). However, when the density of the plasma was increased at constant power the CII emission decreased in both divertors and the inferred source of $\mathrm{C}^{1+}$ decreased dramatically in the outer divertor. The CIV emission actually increased slightly in this case and the inferred $\mathrm{C}^{3+}$ source rate was comparable with the lower density discharge. Again, these data show that the source rate of low charge states of carbon in the outer divertor was not the dominant source for setting the source level of high charge states of carbon that may get into the core.

The responses of $\mathrm{HeII}$ emission and inferred $\mathrm{He}^{1+}$ source rates to power and density variations indicated that the baseline and higher power cases had effective helium recycling in the divertor but the helium ionization source moved outside the divertor in the higher density discharge. The $\mathrm{He} \Pi$ emission and $\mathrm{He}^{1+}$ source increased slightly in the divertors for the higher power discharge (Fig. 8) with little change seen in the inner or outer SOL. At higher density, the $\mathrm{HeIl}$ emission and $\mathrm{He}^{1+}$ source decreased in the divertors but increased by factors of 3 in both the inner and outer SOL regions outside the divertors. This indicates that substantial escape of 
helium neutrals occurred in the high density case compared with the two discharges at lower density.

\section{Discussion}

Taken together the differences in carbon emission between helium and deuterium plasmas are consistent with a model of carbon production in which: 1) the dominant source in helium plasmas is ion physical sputtering, and 2) multiple sources (e.g., ion and neutral physical sputtering, chemical sputtering) all play a role in deuterium plasmas with the dominant source mechanism and location depending on the divertor operating conditions. Comparable $\mathrm{C}^{1+}$ source rates in the outer divertor for the matched helium and deuterium discharges is consistent with the expected ion physical sputtering in the attached outer divertor leg. The variation of $\mathrm{C}^{1+}$ source with power in helium plasmas is also consistent with this model. Helium emission and source rates as a function of power confirm that the outer divertor is in an attached, high recycling condition for the baseline helium discharge. The large reduction of $\mathrm{C}^{1+}$ source in the inner divertor of the helium plasmas compared with deuterium and the insensitivity of this source to power or density variations is consistent with a chemical sputtering mechanism for this source in deuterium that is eliminated in helium. Since the inner divertor is likely detached in these moderate power L-mode plasmas the plasma conditions would not be expected to produce much physical sputtering but would be expected to produce large chemical sputtering yields in deuterium. Finally, the fact that when the density is increased in helium the $\mathrm{C}^{1+}$ source in the outer divertor is significantly reduced is consistent with the expected reduction in outer divertor plasma temperature and ion physical sputtering as detachment is approached. The Hell emission and $\mathrm{He}^{1+}$ source response to density increase also indicated loss of the attached, high recycling condition for the high density plasma.

Finally, the comparisons in this study seem to indicate that the carbon source in the hot attached outer divertor is not the source that determines the source of high ionization states of 
carbon which eventually increase the impurity level of the core plasma. Instead, carbon sources from the inner divertor or the main chamber may dominate the source to the core. In deuterium these sources can be large due to chemical sputtering mechanisms. In helium the chemistry is eliminated and the ionization source of the $\mathrm{C}^{3+}$ charge state is significantly reduced.

\section{Acknowledgment}

This work was performed under EFDA and under the auspices of the U.S. Department of Energy by University of California Lawrence Livermore National Laboratory under Contract W-7405-Eng-48. 


\section{References}

[1] T.D. Rognlien et al., J. Nucl. Mater., 196-198, (1992) 347; T. D. Rognlien et al., Contr. Plasma Phys., 34, (1994) 362; G.R. Smith et al., J. Nucl. Mater., 220-222 (1995) 1024.

[2] J.W. Davis and A.A. Haasz, J. Nucl. Mater., 241-243, (1997) 37.

[3] T.D. Rognlien et al., Phys. Plasmas, 6, (1999) 1851; T.D. Rognlien et al., J. Nucl. Mater., 266-269 (1999) 654.

[4] R.D. Wood et al. Bull. Am. Phys. Soc., 42, (1997) 1844. 


\section{Figure Captions}

Fig. 1. JET equilibrium shape used in this paper. Red flux surfaces are at early time before the vertical X-point sweep, blue surfaces are from near the end of the sweep.

Fig. 2. Time histories of (a) neutral beam injected power, $P_{n b}(M W)$, (b) line averaged electron density, $n_{e}$

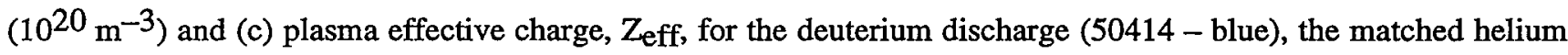
plasma (53981 - red), and helium pulses at higher power (53982 - green) and density (53984 - magenta).

Fig. 3. Time histories of CIII ( $465 \mathrm{~nm})$ emission from the wide angle views of the KS3 spectrometer at (a) the outer divertor, (b) the inner divertor and (c) the horizontal midplane. The plasmas and color scheme are the same as in Fig. 2.

Fig. 4. Comparison of midplane radial profiles of (a) electron density $\mathrm{n}_{\mathrm{e}}\left(10^{20} \mathrm{~m}^{-3}\right)$ and (b) electron temperature $\mathrm{T}_{\mathrm{e}}(\mathrm{eV})$ for helium discharge 53981 between UEDGE simulation (blue line with open squares) and data from the upstream reciprocating probe (similar helium discharge 53974, shifted outboard $1.5 \mathrm{~cm}$ compared with EFIT separatrix). Also shown are density data from the Li-beam diagnostic (KY63, shifted outboard $2 \mathrm{~cm}$ ) and temperature data from edge LIDAR measurements (KE9D shifted outboard $1 \mathrm{~cm}$ ).

Fig. 5. Comparison of inner $(a-c)$ and outer $(d-f)$ target plate profiles of electron density $n_{e}\left(10^{20} m^{-3}\right)[a, d]$, electron temperature $T_{e}(e V)[b, e]$ and ion saturation current $J s a t\left(A / m^{2}\right)(c, f)$ measured by fixed Langmuir probes (red dots) and calculated by UEDGE (blue line with open squares) for helium discharge 53981. All of the probe data from the vertical X-point sweep is shown.

Fig. 6. Comparison of profiles of visible CII $(658 \mathrm{~nm})$ (a) and UV CIV $(31.2 \mathrm{~nm})$ (c) intensities and the inferred source rates of $\mathrm{C}^{1+}$ (b) and $\mathrm{C}^{3+}$ (d) from the $\mathrm{KL} 2 \mathrm{C}$ and $\mathrm{KT} 1$ spectrometers respectively in helium plasma 53981 (red) versus deuterium plasma 50414 (black). For clarity CIV intensity and $C^{3+}$ rate displayed are 10x actual rate. The abscissa for the CII data is the major radius of the view chord at a vertical location of $-1.9 \mathrm{~m}$ from the midplane. For CIV the abscissa is the poloidal angle of the view chord from the outer horizontal midplane. Locations of several points in the divertor are indicated. 
Fig. 7. Comparison of profiles of visible CII (658 nm) (a) and UV CIV (31.2 nm) (c) intensities and the inferred source rates of $\mathrm{C}^{1+}$ (b) and $\mathrm{C}^{3+}$ (d) from $\mathrm{KL} 2 \mathrm{C}$ and $\mathrm{KT} 1$ respectively in helium plasmas for the baseline case 53981 (red), the higher power discharge 53982 (green) and the higher density discharge 53984 (blue).

Fig. 8. Comparison of profiles of He II UV (30.3 nm) intensities (a) and inferred source rates of $\mathrm{He}^{1+}$ (b) from KT1 for the same helium plasmas and color scheme as in Fig. 7. 


$$
0^{-=}
$$




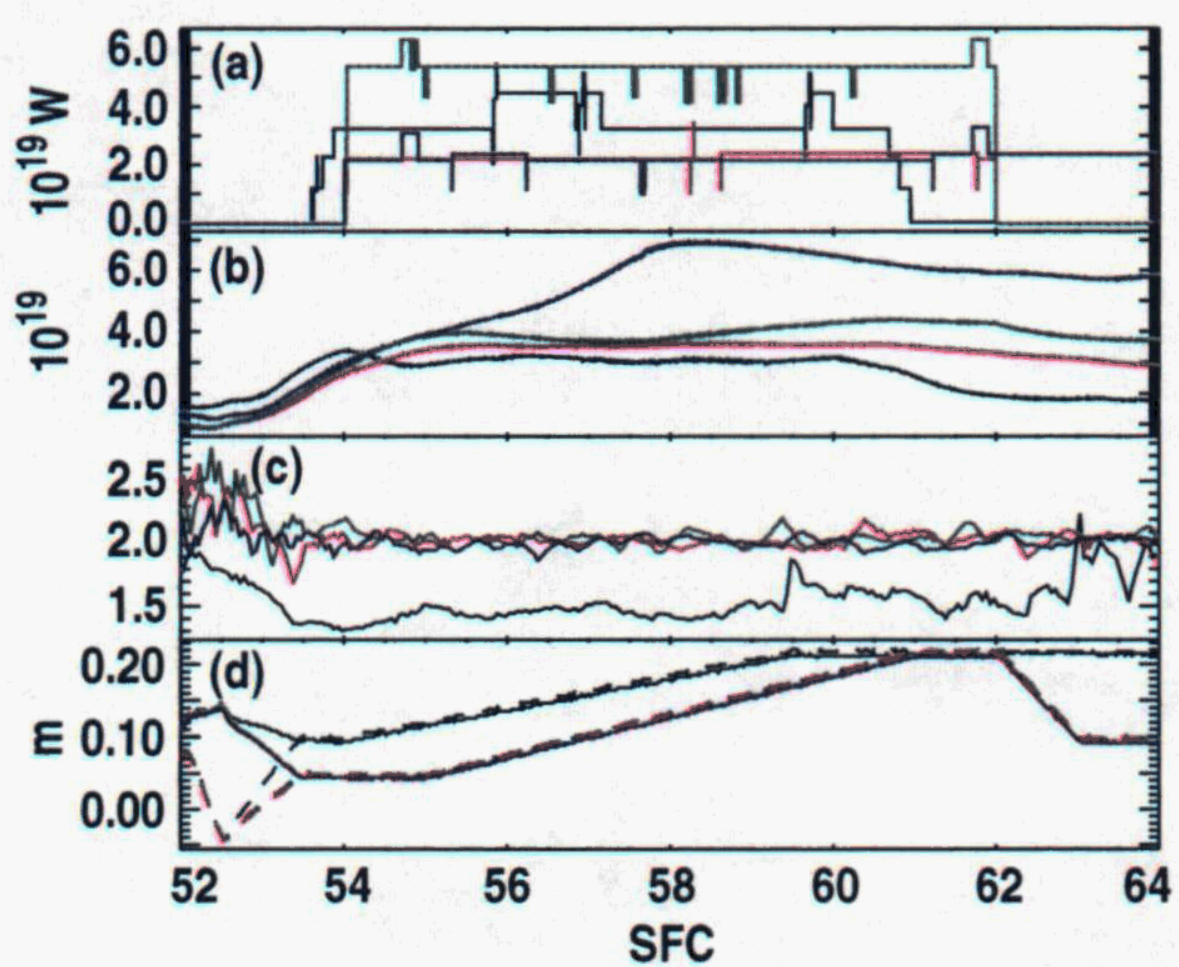




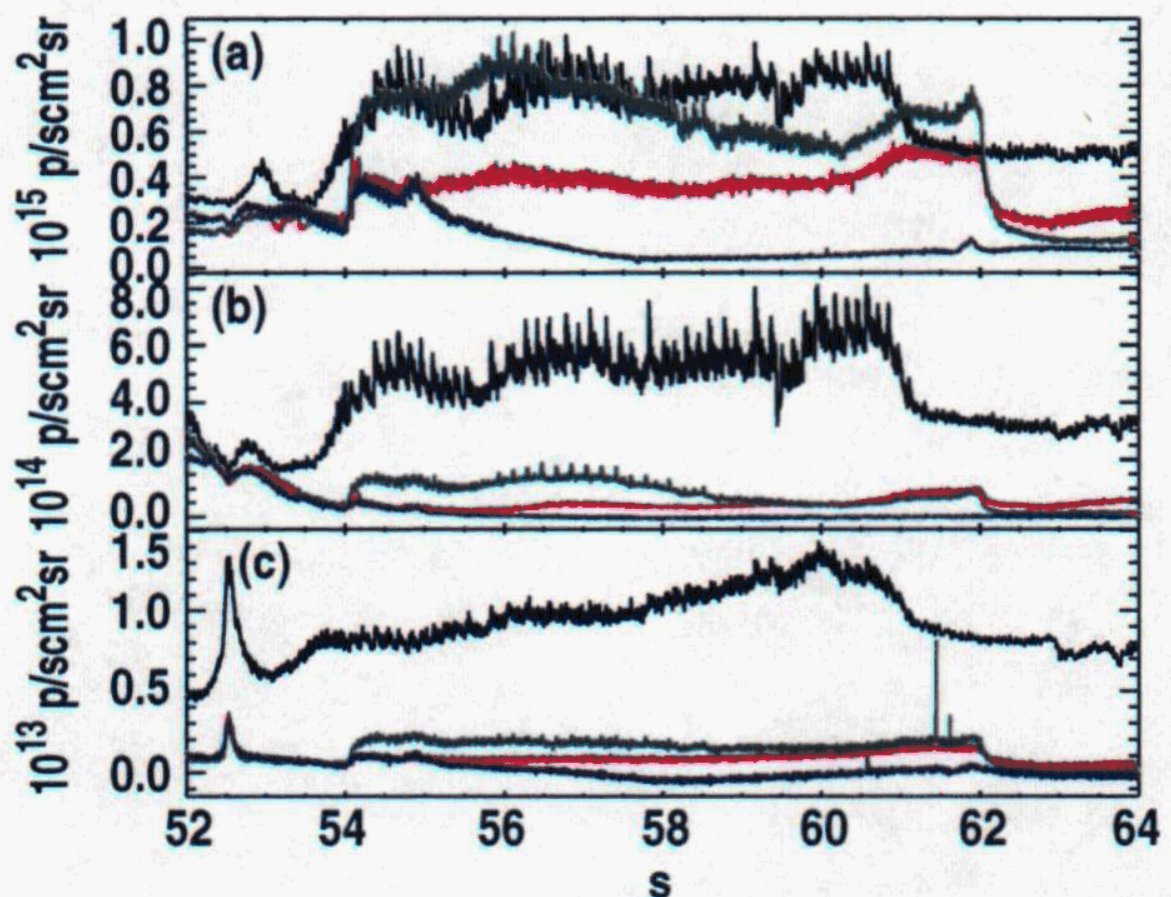



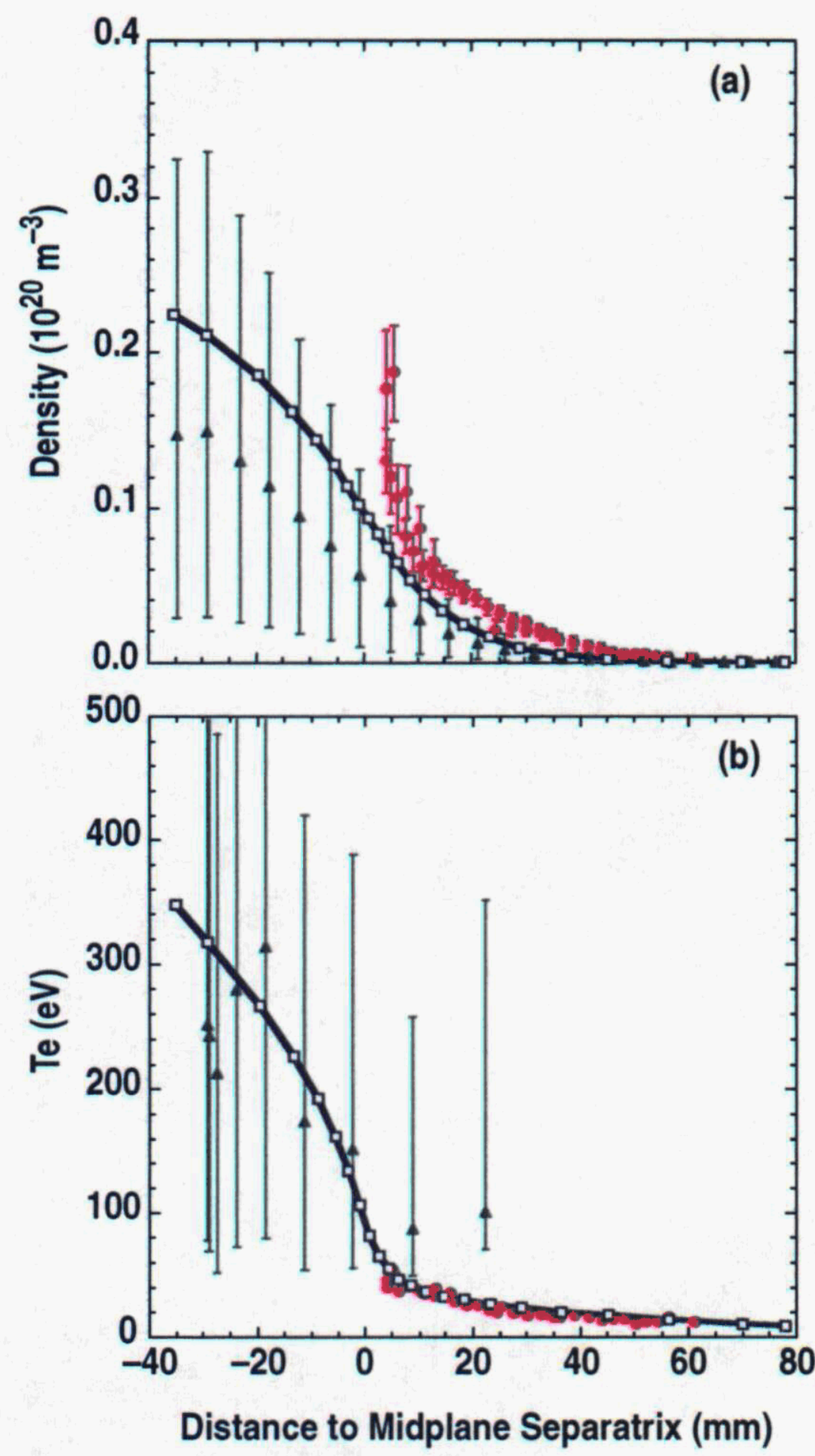

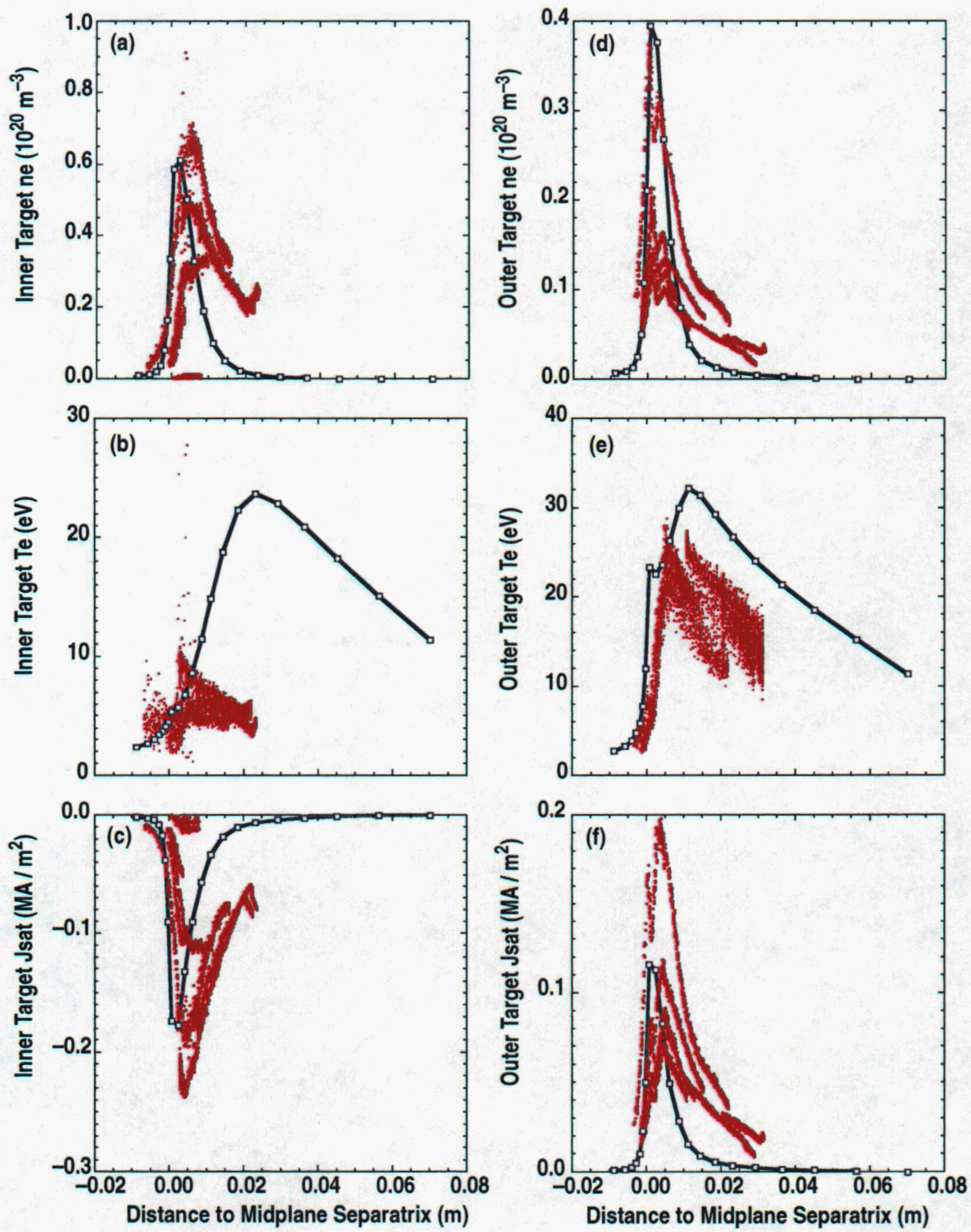

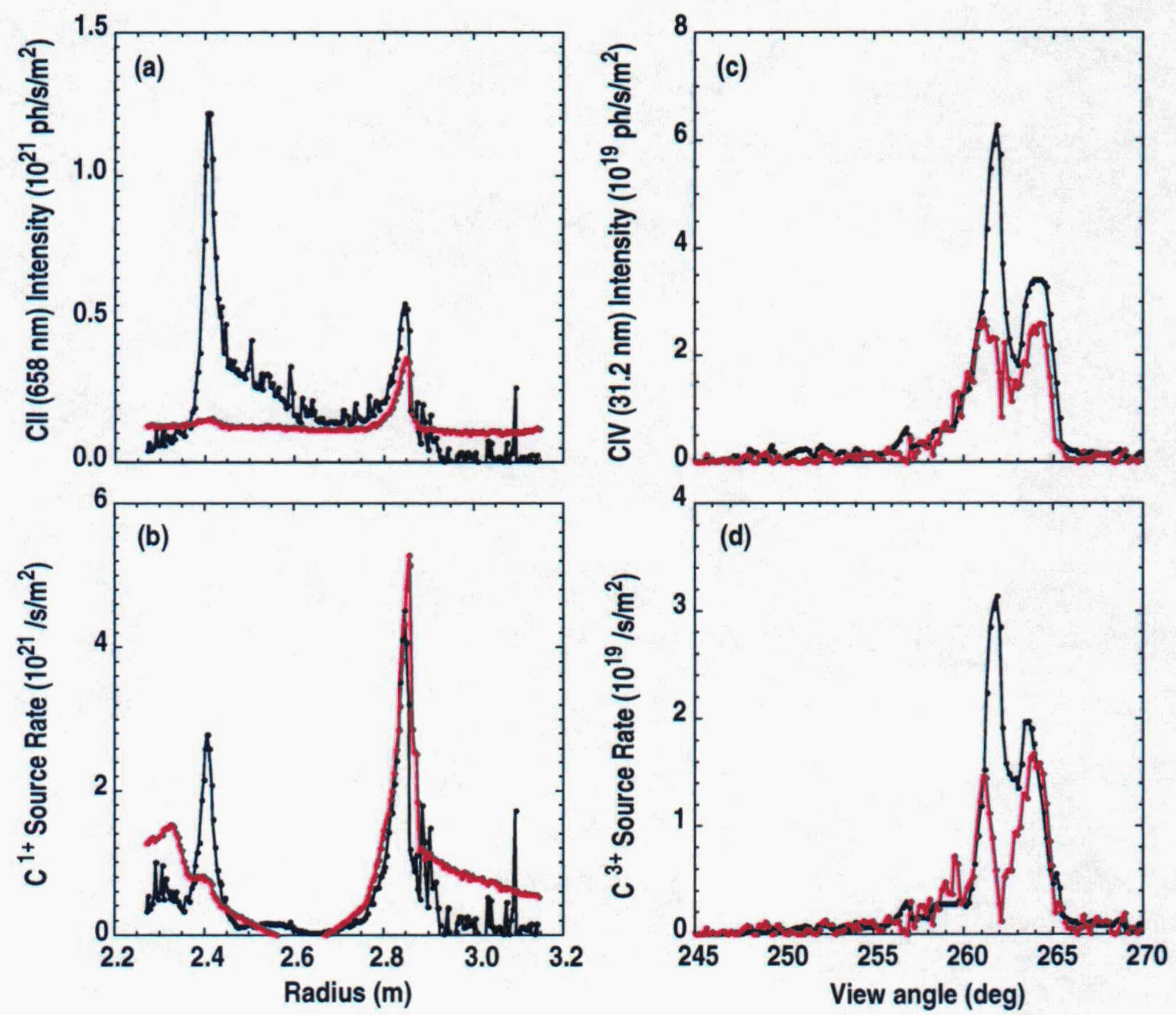

159-02 fig. 6 jy 

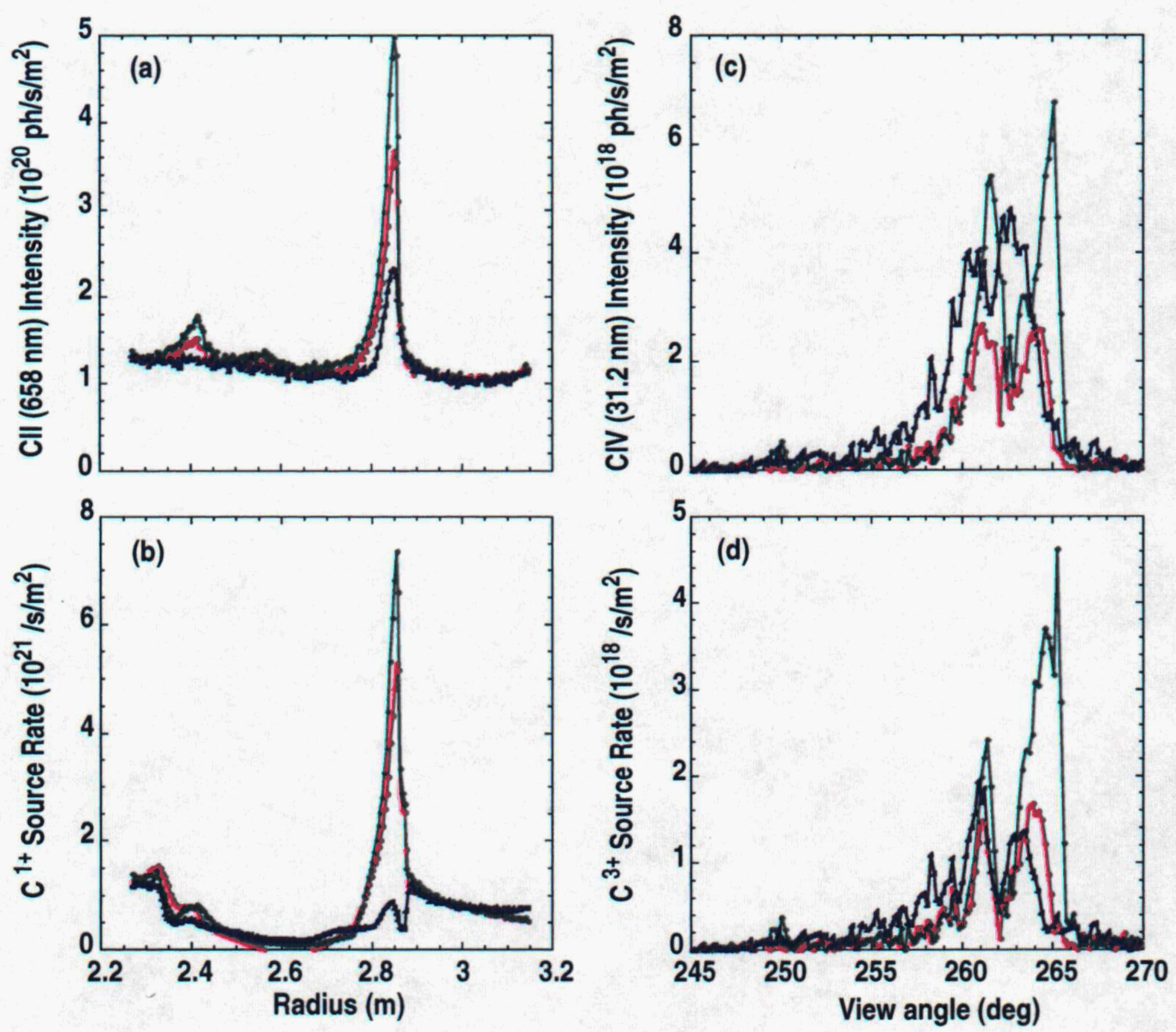

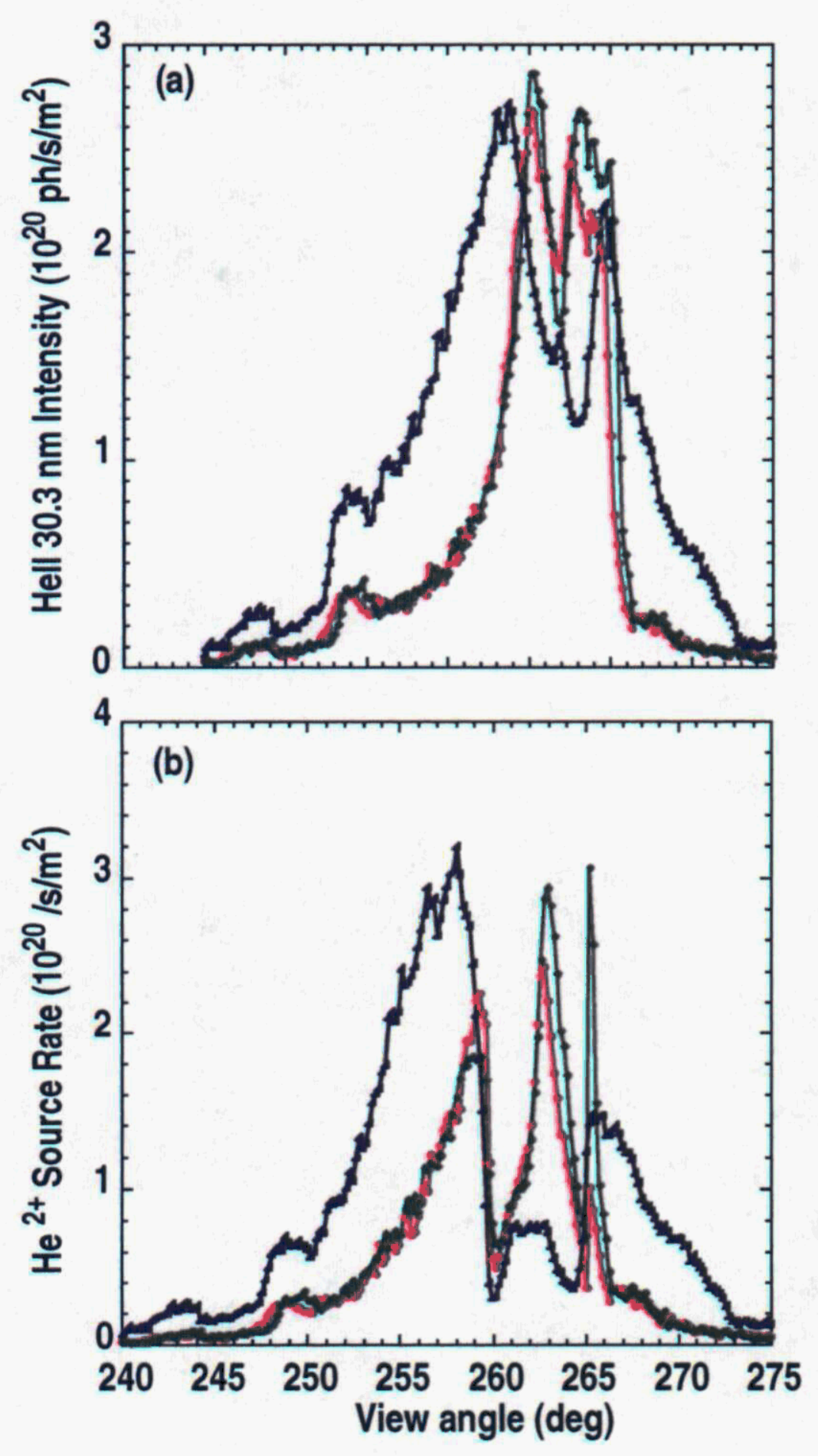

159-02 fig. 8 jy 